\title{
Physiological Sway of Aging on Oxidative Stress and Levels of Some Minerals in Diabetes Type II of Both Female and Male in Sulaimaniyah City.
}

\author{
Maya Ibrahim AL-Samman ${ }^{1 *}$; Sulaf Mustafa Mohammed ${ }^{2}$ \\ $1^{1 *}$ Department of Biology, College of Education for Pure Science, University of Mosul, Mosul, Iraq \\ ${ }^{2}$ Department of Biology, College of Science, University of Sulaimaniyah, Sulaimaniyah, Iraq \\ Email: ${ }^{1 *}$ mayaalsamman91@yahoo.com, ${ }^{2}$ Sulaf.mohammed@univsul.edu.iq
}

(Received February 12, 2019; Accepted January 19, 2020; Available online June 01, 2020)

DOI: 10.33899/edusj.2020.126325.1031, (c) 2020, College of Education for Pure Science, University of Mosul.

This is an open access article under the CC BY 4.0 license (http://creativecommons.org/licenses/by/4.0/).

\begin{abstract}
Diabetes is a metabolic disorders disease characterized by the abnormal high levels of blood sugar due to incomplete or relative deficiency of insulin secretion as well as disorders in carbohydrate, lipid and protein metabolism.

The study aims to evaluate the physiological effects of aging on oxidative stress and mineral levels in diabetes type II by measuring F.B.S,HbA1c\%, levels of a number of important indicators of oxidative stress, level of ferritin ,copper and zinc in the serum. The study included the collecting of 70 blood samples from patients with NIDDM for both sexes in the center of Diabetes and Endocrinology in Sulaimaniyah city. The age of each group in this study ranged between 40-70 years. The study concluded that the rate of both FBS and T.GSH increased with age in diabetic females, the MDA increased with age in diabetic males, and ferritin increased with age in both sexes. Moreover, copper decreased with age in diabetics for both sexes
\end{abstract}

Keywords: Diabetes; Malondialdehyde: Antioxidants; Ferritin: Transition Metals:aging.

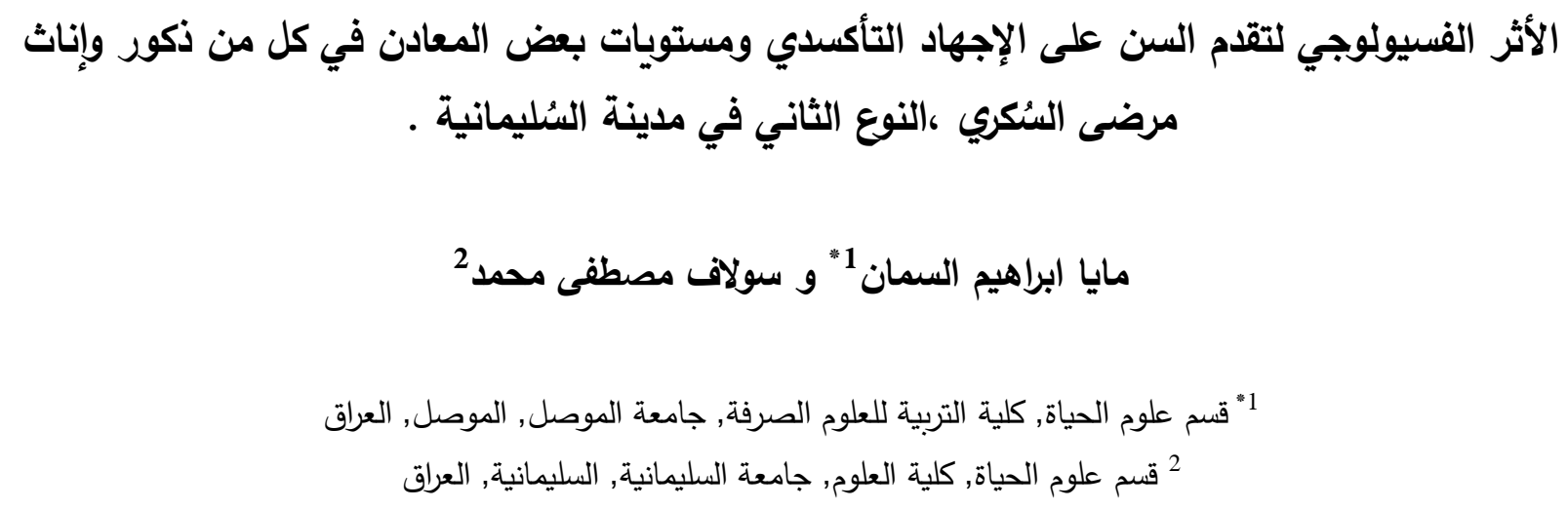




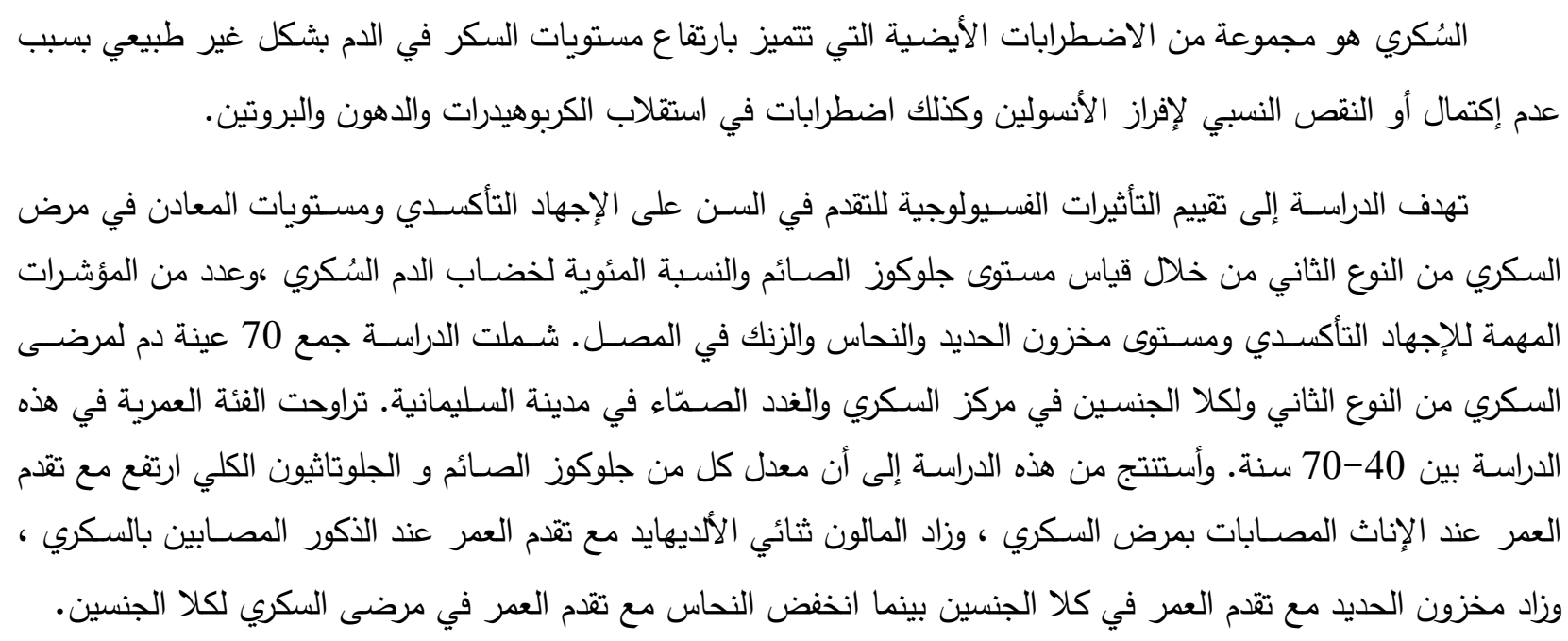

\section{Introduction}

Diabetes is defined as the most common endocrine disorder, or a metabolic disorder characterized by chronic hyperglycemia which affects different organs of the human individual; it also reduces age of human beings; and leads to their death [1]. The persistent high blood sugar leads to the occurrence of what is known as hyperglycemia, Which ultimately seems to be the induction of several biochemical pathways; these biochemical pathways are responsible for the synthesis of free radicals [2]. These are highly reactive chemicals that might be in the form of atoms, molecules, or ions. Free radicals are necessary for a number of intercellular signals that regulate different physiological functions within the human body, but overproduction of free radicals can lead to the so-called oxidative stress caused by hyperactivity[3]. The production of reactive species in the body results in a natural imbalance between the production of systemic manifestations of reactive oxygen and nitrogen species and the ability of the human biological system to easily detoxify the reactive media or repair the resulting damage [3]. In diabetics, free radicals attack many vital molecules in the body, including fats, proteins, and nucleic acids. In lipid molecules, reactive species attack fatty membranes, lipoproteins, and polyunsaturated fatty acids and as a result this process will lead to the production of aldehydes such as Malondialdehyde (MDA) which is the last product of Lipid peroxidation (L.P) that is excessively used as a distinguishing marker of oxidative stress in many studies [2]. The human body has many defense systems against harmful reactive species known as antioxidants, chemical or biological agents that save cells and substances occurring within the cells from destruction caused by unsteady molecules known as free radicals ; these free radicals are classified according to the work they manifest and their kind of antioxidant enzymes such as Superoxide Dismutase (SOD). SOD is the first line of protection that breaks the root of the superoxide anion $\left(\mathrm{O}^{-}\right)$into hydrogen peroxide $(\mathrm{H} 2 \mathrm{O} 2)$ which is converted by another group of enzymes into water.So, it plays a protective role against cellular and histological damage[4]. Non-enzymatic antioxidants is present in all animal and plant cells, for 
example, Glutathione tripeptide antioxidant appears in the human body in several forms, the most important of which is Reduced Glutathione (GSH), which is found in high concentrations in the body and it directly removes free radicals [4]. Blood plasma shows many proteins that suppress the formation of reactive species by binding transitional metal ions, such as ferritin, a non-enzymatic antioxidant that safely stores free iron in the body, which is due to the free iron that is a powerful catalyst for the formation of the reactive species by Fenton reactions [3]. There are non-enzymatic metal antioxidants such as ferritin, zinc and copper which play essential roles in regulating the body's proper metabolism when their(non-enzymatic metal antioxidants) concentrations is present within normal ranges but any imbalance in their concentrations in the body will develop chronic diseases such as diabetes or complications of the disease [5]. Diabetes and weakened glucose tolerance affect a fundamental ratio of older adults. While the ageing process can be related to the modulation in glucose metabolism, including both comparative insulin resistance and islet cell dysfunction, abnormal glucose metabolism is not a necessary compound of ageing. Instead, older adults with diabetes and altered glucose status likely represent a vulnerable subset of the population at high-risk for complications and adverse geriatric syndromes such as accelerated muscle loss, functional disability, frailty, and early mortality[6]. A growing area of research seeks to explore associations of dysglycemia and insulin resistance with the development of adverse outcomes in the elderly and may eventually provide guidelines about the use of future glucose-lowering therapies in this population. So, The aim of the current study is to investigate the effect of the biochemical variables with relation to diabetes in males and females according to age.

\section{Materials and Methods}

Seventy adult individuals ( 38 female and 32 male) aged 40-70 years, are divided into three group's, the mean age of the first group ranges from (40_50) years, while the second group's mean age ranges from (50_60) years, whereas the last group mean age ranges from (60_70) years with clinical and laboratory diagnosis of DM2 from Diabetes and endocrine center in Sulaimaniyah city participated in the study. These patients were carefully selected according to the following study criteria: 1- they are diabetics for more than a year, 2- not diagnosed with heart disease, liver, and chronic kidney, 3- not diagnosed with infected malignant tumors, 4- not diagnosed with endocrine diseases, 5- not diagnosed with Retinopathy or neuropathy due to diabetes complications, 6- they do not take any type of vitamin or mineral supplements, and 7- they are not smokers and not alcoholics.

Blood samples have been collected after at least eight hours of fasting between 8:30 am to 1:30 am and they have been prepared for all biochemical analyses .

\section{Fasting blood Sugar (F.B.S)}

By using the Roche-Hitachi kit with the Cobas c311, enzymatic reference Method with Hexokinase have been used to measure the level of serum glucose at the 340nm absorbancy [7]. 


\section{HbA1C \%.}

The stable and variable form of cumulative sugar can be individually designed in this test depending only on the chromatogram without the need of the manual pre-treatment. This analysis requires three minutes using the HLC-723GX kit with Tosoh automated glycohemoglobin [8].

\section{Serum Malondialdehyde Concentration (MDA).}

Malondialdehyde reacts with thiobarbeturic acid (TBA) under temperature up to $90{ }^{\circ} \mathrm{C}$ and in an acidic medium to form a pink MDA-TBA complex as a final product, then it is detected by spectrophotometer with a wavelength of $532 \mathrm{~nm}$ [9].

\section{Serum Superoxide Dismutase Concentration (SOD).}

Superoxide Dismutase activity was measured by WST-1 using superoxide Dismutase Assay kit ( Elabscience), with a wavelength $450 \mathrm{~nm}$, with Elisa.

\section{Total Serum Glutathione Concentration (T.GSH)}

Serum total glutathione was measured by the periodic reaction of 5,5-dithio-bis - (2nitrobenzoic acid) (DTNB), using T.GSH Assay kit (Elabscience) .The first absorbance was measured by the plate reader with a wavelength of (405) $\mathrm{nm}$ after a period of (30) seconds then the second absorbance was measured immediately after (360) seconds with Elisa.

\section{Serum Ferritin Concentration}

In this test, two monoclonal antibodies have been used to form a sandwich compound. The test uses the total duration of the assay (18) minutes with the RocheHitachi kit (cobas e411)[10].

\section{Serum Zinc Concentration}

Zinc is formed with 2-(5-brom-2-pyridylazo)-5- (N-propyl-N-Sulfopropylamino)- Phenol complex called The Red Chelate. The increase in absorption is related to the condensation of zinc in the specimen using the ready kit (SDI). After that, the absorbance at the wavelength (560) $\mathrm{nm}$ has been read using a spectrophotometer [11].

\section{Serum Copper Concentration}

The $\mathrm{Cu}+2$ copperions reacts with the Di-Br-PAESA chromogen to form a blue compound. The blue compound intensity is relative with copper condensation in the specimen using (LTA) kit. The absorbance of the sample with a wavelength (580) nm has been measured using a spectrophotometer [12].

\section{Statistical Analysis}


The data were analyzed according to the simple experimental system, and by using the complete random design The averages were compared with Duncan multi-range test.

\section{Outcomes and Debate}

Table (1) manifests the effect of age on the rate (F.B.S) and(HbA1C) of both sexes in diabetic patients. It was found that the F.B.S rate in female was significantly increased $(p<0.01)$ with the increase in age. On the other hand, there were no significant changes in F.B.S in the different ages of the male while $\mathrm{HbA} 1 \mathrm{C} \%$ was not significantly affected by age in both sexes for the three age groups. The reason for the difference in age-related FBS rate is due to the effect of female sex hormones which decrease with age. FBS decreases to increase the resistance of body cells to insulin action, especially the hormone estrogen which protects the body from high blood sugar by its direct impact on the balance of glucose and insulin. It reduces the production of hepatic glucose and promotes muscle glucose transport. Estrogen has antioxidant properties and increased expression of genes associated with longevity, including genes that encode enzymatic antioxidant like Superoxide dismutase ,Glutathione peroxidase. It also has a role in the metabolism of adipose tissue[13]. Menopause is related to metabolic diseases; it increased fatness. Visceral fat is d eposited because of a lack of estrogen, which prevents the deposition of visceral fat and maintains the distribution of fatty tissue as it promotes the use of fats as fuel [13]. HbA1c\% has been tested for critical and accurate detection of diabetes[14]. The current- study, it has been noticed that when the two sexes get older, the increased percentage of HbA1C is more in females than that of males, since the cause may be due to females having anemia when they are older, which is ultimately related to low hormones and menopause [23]. This test is not affected by the introduction of modern food as it measures blood sugar in ten to twelve weeks[14].

Table 1: Age effect on fasting glucose ( $\mathrm{mg} / \mathrm{dL}$ ) and percentage of Glycosylated Heamoglobin \pm standard deviation in blood samples of diabetic patients for both sexes.

\begin{tabular}{|c|c|c|c|}
\hline \multirow[t]{2}{*}{ Genders } & \multirow[t]{2}{*}{ Age Groups } & $\begin{array}{c}\text { F.B.S } \\
(\mathrm{mg} / \mathrm{dl})\end{array}$ & $\begin{array}{c}\text { HbAlc \% } \\
(\%)\end{array}$ \\
\hline & & Mean \pm SD & Mean \pm SD \\
\hline \multirow{3}{*}{ Females } & $\left(40 \_50\right)$ & $146.95 \pm 15.25^{\mathrm{C}}$ & $8.71 \pm 1.67^{\mathrm{A}}$ \\
\hline & (50_60) & $197.77 \pm 40.52^{\mathrm{B}}$ & $9.28 \pm 1.28^{\mathrm{A}}$ \\
\hline & $\left(60 \_70\right)$ & $371.25 \pm 22.77^{\mathrm{A}}$ & $9.65 \pm 2.43 \quad \mathrm{~A}$ \\
\hline \multirow{3}{*}{ Males } & (40_50) & $163.66 \pm 13.21^{\mathrm{A}}$ & $9.86 \pm 1.55 \mathrm{~A}$ \\
\hline & $\left(50 \_60\right)$ & $151.10 \pm 15.79^{\mathrm{A}}$ & $8.58 \pm 2.39^{\mathrm{A}}$ \\
\hline & $\left(60 \_70\right)$ & $156.33 \pm 20.05^{\mathrm{A}}$ & $8.33 \pm 1.94 \mathrm{~A}$ \\
\hline
\end{tabular}


Table (2) manifests the effect of age on the rate of MDA, SOD\% and T.GSH, in both sexes. MDA levels increased significantly $(\mathrm{P}<0.1)$ in the $(60-70)$ years aged male group comparing to (40-50) and (50-60) years old groups.

Most of the molecules in human body are non-radicals. Any reactive free radical is created to react with a non-radical in humans. The biological molecules which are present in our body are at danger of being attacked by free radicals, which seem to be one of the defenitive popular pathways of cell damage. Such distructed molecules can weaken cell functions and lead to ageing and cell deatl ultimately resulting in diseased conditions. There are three important reactions in this type; they are: lipid oxidation, protein oxidation and DNA damage [15]. In the present study MDA as an oxidative stress index and its very important indicator of lipid peroxidation have been used .

The present study reveals that aging has increased the oxidative stress in male DMT2 patients as specified by the consderable increase in MDA serum as confirmed by the results of a study [16], while oxidative stress has not been affected in females. The main reason is probably having antioxidant vitamin supplements or taking synthetic antioxidant supplements compared to males.

Moreover,SOD\% does not reveal any significant changes in both sexes for all different ages. Another important Antioxidant is total glutathione which is used to show the ability of the body to naturalize the sway of free radicals in diabetics and the current steady reveals un expected results where the level of T. GSH in the female increased significantly $(\mathrm{P}<0.01)$ in the group of (6070)years old compared to another aged groups while in males, as the table showed, the level of T.GSH increased significantly $(\mathrm{p}<0.01)$ in the age group $(50-60)$ matched to the younger and older aged groups. It may be due to a different diet or due to some antioxidants.

Antioxidants are substances able to slow or inhibit the oxidation of other molecules.

Age has shown a variation in its effect on antioxidants for both sexes Generally, Antioxidant production in the body may decrease by aging, which reduces the body's ability to balance the quantity of free radical manufacture with the ability of the Antioxidant system to keep these free radicals stable to protect them[1]. In the elderly, it seems obvious that calorie's intake and the lack of culture to select foods that is full of natural Antioxidants, which strengthen the body's natural antioxidant system, as well as not taking Antioxidant supplements or some of them lead to reduce diabetes. 
Table (2): Effect of Age on Malondialdehyde ( $\mu \mathrm{mol} / \mathrm{L}$ ), Super Oxide Dismutase (\%) and Total Glutathione $(\mu \mathrm{mol} / \mathrm{L}) \pm$ Standard Deviation in Serum Samples of Diabetic Patients in Both Sexes.

\begin{tabular}{|c|c|c|c|c|}
\hline Genders & $\begin{array}{c}\text { Age } \\
\text { groups }\end{array}$ & $\begin{array}{c}\text { MDA } \\
(\mu \mathrm{mol} / \mathrm{L}) \\
\text { Mean } \pm \text { SD }\end{array}$ & $\begin{array}{c}\text { SOD } \\
(\%)\end{array}$ & $\begin{array}{c}\text { T.GSH } \\
(\mu \mathrm{mol} / \mathrm{L})\end{array}$ \\
\hline \multirow{4}{*}{ Females } & $\left(40 \_50\right)$ & $4.49 \pm 1.01^{\mathrm{A}}$ & $63.49 \pm 7.08^{\mathrm{A}}$ & $9.15 \pm 2.96^{\mathrm{B}}$ \\
\cline { 2 - 6 } & $\left(50 \_60\right)$ & $4.51 \pm 1.12^{\mathrm{A}}$ & $65.66 \pm 7.19^{\mathrm{A}}$ & $10.38 \pm 2.14^{\mathrm{AB}}$ \\
\cline { 2 - 6 } & $\left(60 \_70\right)$ & $4.22 \pm 1.36^{\mathrm{A}}$ & $64.75 \pm 5.87^{\mathrm{A}}$ & $12.50 \pm 2.12^{\mathrm{A}}$ \\
\hline \multirow{3}{*}{ Males } & $\left(40 \_50\right)$ & $3.81 \pm 1.25^{\mathrm{B}}$ & $62.43 \pm 12.33^{\mathrm{A}}$ & $5.73 \pm 1.80^{\mathrm{B}}$ \\
\cline { 2 - 6 } & $\left(50 \_60\right)$ & $4.25 \pm 1.17^{\mathrm{B}}$ & $63.98 \pm 11.95^{\mathrm{A}}$ & $9.28 \pm 2.65^{\mathrm{A}}$ \\
\cline { 2 - 6 } & $\left(60 \_70\right)$ & $5.84 \pm 0.42^{\mathrm{A}}$ & $68.20 \pm 7.59^{\mathrm{A}}$ & $6.90 \pm 1.60^{\mathrm{B}}$ \\
\hline
\end{tabular}

Table (3) shows the effect of age on the rate of ferritin, zinc and copper for both sexes in diabetic patients. The results have shown a significant increase $(\mathrm{p}<0.01)$ in the level of ferritin of group (6070) age in both sexes. The significant rise in the level of ferritin may be due to the low level of insulin in the body due to lack of free iron absorption through the iron receptors known as transferrin, the main protein in the blood that binds and transports iron through the body. The protein is necessary to keep iron inert in a non-oxidized form $(\mathrm{Fe}+3)$, and this came from the results of the study[17] and [18].The study found that high blood sugar levels were associated with high ferritin in diabetic patients and as a result, free iron deposition in pancreatic cells increases with age[19]. Age had no significant effect on the rate of zinc in both sexes, while copper rate showed a significant decrease $(p<0.01)$ with the increase in age for both females and males. The reason for the decrease in zinc in patients may be due to high blood sugar and the increase in the amount of urea in diabetics due to increased blood glucose level which leads to the release of zinc in the diuresis and is not compensated by absorption from the intestine or lack of excretion of them in addition to lack of dietary intake containing zinc and lack taking zinc supplements with age[20]. The main protein that is responsible for transporting zinc from the cytoplasm to secretory vesicles, called Zinc transporter protein member 8 (ZnT8), is thought to regulate the concentration of zinc in beta cells in the pancreas[21].The fat metabolism disturbance that breaks down cells results in an imbalance in the distribution of ions and the breakdown of copper-associated proteins, and oxidation of lipid membrane and Proteins that happened in diabetes divide nucleic acids and thus cell death[22] which might be the cause of serum metal disturbance. 
Table (3) : Age effect on Ferritin ( $\mathrm{ng} / \mathrm{ml}$ ), zinc ( $\mu \mathrm{g} / \mathrm{dl})$, and copper ( $\mu \mathrm{g} / \mathrm{dl}) \pm$ standard deviation in serum samples for diabetic patients in both sexes.

\begin{tabular}{|c|c|c|c|c|}
\hline Gender & $\begin{array}{c}\text { Age } \\
\text { Groups }\end{array}$ & $\begin{array}{l}\text { Ferritin } \\
(\mathrm{Ng} / \mathrm{ml})\end{array}$ & $\begin{array}{c}\text { Zinc } \\
(\mu \mathrm{g} / \mathrm{dl})\end{array}$ & $\begin{array}{l}\text { Copper } \\
(\mu \mathrm{g} / \mathrm{dl})\end{array}$ \\
\hline s & & Mean $\pm \mathrm{SD}$ & Mean \pm SD & Mean \pm SD \\
\hline \multirow{3}{*}{$\begin{array}{c}\text { Female } \\
\text { s }\end{array}$} & (40_50) & $117.55 \pm 20.12^{\mathrm{B}}$ & $67.95 \pm 9.31^{\mathrm{A}}$ & $167.69 \pm 28.94^{\mathrm{A}}$ \\
\hline & $\left(50 \_60\right)$ & $106.23 \pm 18.40^{\mathrm{B}}$ & $74.97 \pm 15.68^{\mathrm{A}}$ & $161.26 \pm 28.02^{\mathrm{AB}}$ \\
\hline & $\begin{array}{l}\left(60 \_70\right) \\
\end{array}$ & $136.81 \pm 5.76^{\mathrm{A}}$ & $68.12 \pm 14.80^{\mathrm{A}}$ & $138.58 \pm 13.32^{\mathrm{C}}$ \\
\hline \multirow{3}{*}{ Males } & (40_50) & $126.11 \pm 9.24^{\mathrm{B}}$ & $79.05 \pm 5.44^{\mathrm{A}}$ & $168.57 \pm 18.74^{\mathrm{A}}$ \\
\hline & (50_60) & $102.91 \pm 27.10^{\mathrm{B}}$ & $71.61 \pm 14.86^{\mathrm{A}}$ & $133.12 \pm 14.99^{\mathrm{B}}$ \\
\hline & (60_70) & $335.32 \pm 34.57^{\mathrm{A}}$ & $74.46 \pm 9.17^{\mathrm{A}}$ & $111.67 \pm 19.16^{\mathrm{C}}$ \\
\hline
\end{tabular}

\section{Conclusion}

The current study reveals that there is a great relation between aging and level of antioxidants, lipid peroxidation, and some metals in the diabetic patient in males compared to females. This is due to health care attention in females compared to males confirming why some parameters have not changed significantly in elderly female.

\section{Acknowledegements}

I would like to thank those who work in the department of Biology /College of education for pure science /University of Mosul for their constant help . I would also like to thank those who support me in the department of Biology /College of Science/ University of Sulaimaniyah for their constant aid.

\section{References}

[1] Madmoli, M.; Dehcheshmeh, Z. M.; Rafi, A.; Kord, Z.; Mobarez, F.and Darabiyan, P. (2019). Medical Science, 23(95): 63-68.

[2] Nagarajrao, R. A. M. P. and Alharbi, S. A. (2018). Asian Journal of Pharmaceutical and Clinical Research, 11(1): 363-368.

[3] Mirończuk-Chodakowska, I.; Witkowska, A. M. and Zujko, M. E. (2018). Advances in medical sciences, 63(1): 68-78.doi: 10.1016 / j.advms.2017.05.005.

[4] Thakur, P.; Kumar, A. and Kumar, A. (2018). Journal of drug targeting, 26(9): 766-776.doi: 10.1080/1061186X.2017.1419478. 
[5] Adnan, M. T.; Amin, M. N.; Uddin, M. G.; Hussain, M. S.; Sarwar, M. S.; Hossain, M. K. and Islam, M. S. (2019). Diabetes \& Metabolic Syndrome: Clinical Research \& Reviews, 13(2): 933938.doi:10.1016/j.dsx.2018.12.022.

[6] Kalyani, R. R., \& Egan, J. M. (2013). Endocrinology and metabolism clinicals of North America, 42(2), 333-347. doi:10.1016 / j.ecl.2013.02.010.

[7] Marchand, O. (2018). University of Otago.New Zealand.

[8] Steffes, M.; Cleary, P.; Goldstein, D.; Little, R.; Wiedmeyer, H. M.; Rohlfing, C. and Nowicki, M. (2005). Clinical chemistry, 51(4): 753-758.doi: 10.1373/clinchem.2004.042143 Published March 2005.

[9] Uchiyama, M. and Mihara, M. (1978). Analytical biochemistry, 86(1): 271-278.doi: 10.1016/0003-2697(78)90342-1.

[10] Blackmore, S.; Hamilton, M.; Lee, A.; Worwood, M.; Brierley, M.; Heath, A.and Thorpe, S. J. (2008). Clinical chemistry and laboratory medicine, 46(10): 1450-1457.doi: 10.1515/CCLM.2008.304.

[11] Johnsen, Ø. and Eliasson, R. (1987). International Journal of Andrology, 10(2): 435-440.doi: 10.1111/ j.1365-2605.1987. tb00216.x.

[12] Abe, A. and yiamashita,S. (1989). CliniclChemistry, 35(4): 552-554.

[13] Geer, E. B.and Shen, W. (2009). Gender medicine, 6(1): 60-75.doi: 10.1016/j.genm.2009.02.002.

[14] Thanpari, C.; Takhelmayum, R.; Yadav, N. K.; Shrewastwa, M. K.; Thapa, P. and Mittal, R. K. (2017). International Journal of Diabetes in Developing Countries, 37(2): 103-106.

[15] Tandon, V.; Gupta, B.M. and Tandon, R. (2005). International Journal of current science and practice, 12: 143-148.

[16] Kassim, M. N. (2011). Al Taqani Journal, 24(4): 70-78.

[17] Ford, E. S. and Cogswell, M. E. (1999). Diabetes care, 22(12): 1978-1983.doi: 10.2337/diacare.22.12.1978.

[18] Fernández-Real, J. M.; López-Bermejo, A. and Ricart, W. (2002). Diabetes Care, 51(8): 23482354.doi: 10.2337/diabetes.51.8.2348.

[19] Awadallah, S. (2013). Advances in Clinical Chemistry,60: 85-128. doi: 10.1016/B978-0-12407681-5.00003-9.

[20] Abduallateef, N. and Khalied, S. (2012). AL-yarmouk Journal, (1): 5-21. 
[21] Huang, Q.; Du, J.; Merriman, C. and Gong, Z. (2019). International journal of endocrinology,2019:1-11.doi:10.1155/2019/1524905.

[22] Lowe, J.; Taveira-da-Silva, R. and Hilário-Souza, E. (2017). International Union of Biochemistry and Molecular Biology, 69(4): 255-262.

[23] Christy, A. L.; Manjrekar, P. A.; Babu, R. P.and Hegde, A. (2014). Iranian biomedical journal, 18(2): 88-93.doi: 10.6091/ibj.1257.2014. 